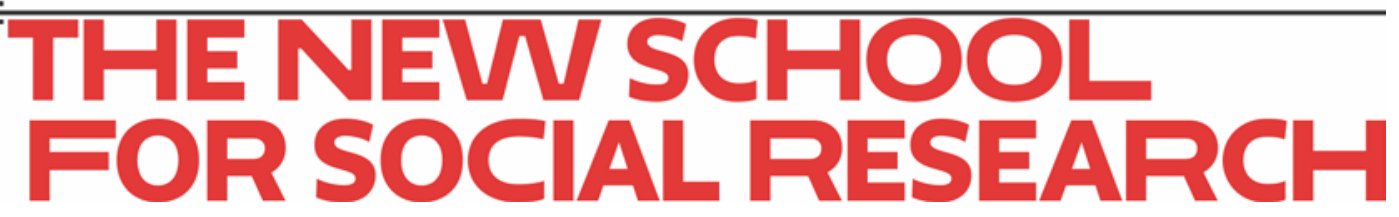

Mark Setterfield

\title{
Tolerable ranges of variation in the rate of capacity utilization and corridor instability: a reply to Florian Botte
}

May 2019

Working Paper 05/2019

Department of Economics

The New School for Social Research 


\title{
Tolerable ranges of variation in the rate of capacity utilization and corridor instability: a reply to Florian Botte
}

\author{
Mark Setterfield*
}

May 28, 2019

\begin{abstract}
This reply to Botte (2019) responds to criticisms of the methods used to estimate the normal rate of capacity utilization and a tolerable interval of variation in the actual rate of capacity utilization around the normal rate in Setterfield (2019a). It concludes with some further reflections on the concept of corridor instability.
\end{abstract}

JEL codes: E11, E12, O41

Keywords: Normal rate of capacity utilization, Harrodian instability, corridor instability.

\section{Introduction}

Botte (2019) makes some astute and constructive criticisms of the methods used in Setterfield (2019a) to estimate both the normal rate of capacity utilization itself, and a tolerable interval of variation in the actual rate of capacity utilization around the normal rate. The value of these criticisms is then illustrated by discussion of a "muddy slump" scenario, in which recovery from a severe recession is impeded by endogenous variation in the now-dynamic tolerable interval of variation in the actual rate of utilization. Botte 2019) contains precisely the sort of analysis that I had hoped my original paper would provoke. I continue to regard the latter as an "opening salvo" rather than a "final word" on a series of topics that may yet

\footnotetext{
${ }^{*}$ Department of Economics, New School for Social Research; mark.setterfield@newschool.edu.
} 
point towards an appropriate synthesis of seemingly-antagonistic Harrodian and Kaleckian macrodynamics.$^{1}$

In the spirit of Botte's constructive criticisms, this reply offers further thoughts on both the estimation of the normal rate and the tolerable interval of variation in the actual rate of capacity utilization. It concludes with some reflections on the implications for analysis based on the concept of corridor instability.

\section{Estimating the normal rate of capacity utilization}

The process of extracting unobserved trends from raw data is a vexed and vexing issue, as recent contributions focused on this issue attest (Hamilton, 2018; Schüler, 2019). The process of then imbuing these trends with behavioural meaning - as when the trend in measured capacity utilization rates (however extracted) is interpreted as the normal rate of capacity utilization - further complicates matters. It is perhaps not surprising, then, that the first concern with my original paper raised by Botte (2019) is its use of the Hodrick-Prescott (HP) filter to derive an estimate of the normal rate of capacity utilization. The general point that he makes - that there is no generally accepted method of trend extraction and that different methods may be more or less suited to different circumstances - is well taken. Indeed, this is all the more so because the properties of the trend (normal?) rate of capacity utilization derived from the same observations of the actual capacity utilization rate may not be robust to changes in filtering methods (Avritzer, 2019). There is, however, one potentially important point that is missed by Botte (2019) and that factors into this "choice of filtering technique" debate. This concerns the choice of closure that reflects underlying behavioural

\footnotetext{
${ }^{1}$ Synthesising Harrod and Kalecki is not a new idea - see, for example, Kriesler and Nevile $(2012)$ and Setterfield (2019b). It has yet to find expression in long-run macrodynamics, however, where the stable, steady-state equilibrium analysis that dominates Kaleckian macrodynamics (Hein et al., 2011, 2012) seems to be at odds with the embrace of instability within bounds - the so-called "corridor instability" approach - favoured by Harrodians (Skott, 2010; Fazzari et al., 2013).
} 
interpretation of the normal rate of capacity utilization itself. Two such closures can be identified:

$$
\begin{gathered}
u_{n}=\bar{u}_{n} \\
\dot{u}_{n}=\alpha\left(u-u_{n}\right)
\end{gathered}
$$

where $u$ and $u_{n}$ denote the actual and normal rates of capacity utilization, respectively. Botte (2019) implicitly appeals to the closure in equation (2), which implies that the normal rate of capacity utilization displays hysteresis, varying endogenously in response to departures of the actual rate of capacity utilization from the normal rate Lavoie, 1995, 1996, 2010; Dutt, 1997, 2010; Cassetti, 2006; Commendatore, 2006; Nikiforos, 2016). Hence note that from (2):

$$
\dot{u}_{n} \simeq u_{n t}-u_{n t-1}=\alpha\left(u_{t-1}-u_{n t-1}\right)=\psi u_{n t-1}+(1-\psi) u_{t-1}
$$

where $t$ - subscripts denote time periods and $\psi=1-\alpha$. In other words, the method used in Botte (2019) to derive an estimate of the normal rate (on the right-hand-side of (3)) is directly related to the hysteresis closure in (??). Equation (3) is introduced as a preferable substitute for the HP filter on the grounds that "it does not require firms to possess unrealistic forecasting abilities" (Botte, 2019, p.??) whereas the HP filter - which uses future as well as past actual values of a variable to derive the trend value of the same variable - makes unwarranted assumptions about the foresight possessed by firms when they determine the normal rate of capacity utilization in an environment of fundamental uncertainty. In and of itself this is all very well. But as noted, equation (3) can be associated uniquely with the closure in equation (2). In Setterfield (2019a), however, the closure in equation (1) is explicitly used. This is incompatible with equation (2) and hence the trend-extraction 
method in equation (3). Equation (1) involves a different behavioural treatment of the normal rate of capacity utilization. Instead of interpreting the latter as being derived with reference to the actual rate of capacity utilization (in which case concerns with the exercise of foresight, given the nature of the decision making environment, become paramount) equation (1) describes an exogenously-determined parameter. The latter may, in fact, have structural determinants that themselves change over time, causing variations in $u_{n}$ (Skott, 2012). But these variations are quite independent of $u$, whether anticipated or experienced in the recent past. In this context, actual capacity utilization data are used to estimate the normal rate of capacity utilization only because the latter is unobserved, and not because of a behavioural postulate stating that the normal rate is determined by reference to the actual rate. Hence the use of the HP filter as a statistical technique for estimating the normal rate of capacity utilization does not have the same implications in my original paper as it does for Botte (2019), because of our differing behavioural treatments of the normal rate as captured by the different (implicit or explicit) appeal we make to the closures in equations (1) and (2).

This having been said, a larger point remains on which we can both agree: that within the larger problem of extracting unobserved trends from observed data, there exists a more specific problem for those interested in using the actual rate of capacity utilization to estimate the normal rate of capacity utilization - namely, that one's choice of filtering technique should be sensitive to one's behavioural treatment of the normal rate, as reflected in the different plausible closures in equations (1) and (2). Botte (2019) is to be applauded for drawing attention to this point. 


\section{Estimating a tolerable interval of variation around the normal rate}

In Setterfield (2019a), I suggest first-pass measures of the tolerable range of variation in the actual rate of capacity utilization around its normal rate that are based on the standard deviation of the actual rate of capacity utilization over the period 1990-2007. Botte (2019) criticizes this approach on the basis that it suppresses variation in macroeconomic volatility over a near two-decade period. He proposes instead use of a variable "restlessness indicator" that, for each period, is based on the standard deviation of the capacity utilization rate over the previous $n$ periods.

Whether or not this restlessness indicator is the best possible measure of variation in macroeconomic volatility, the point made by Botte (2019) is well taken: macroeconomic volatility does vary over time; and any behavioural theory of future-oriented behaviour (such as whether or not to change investment plans on the basis of departures of the actual from the normal rate of capacity utilization) that is based on fundamental uncertainty, under which conditions recent events can be expected to weigh heavily on decision making, should take this into account. In fact, such is the importance of the point made by Botte (2019) that it is worth noting that variations in macroeconomic volatility may affect not only whether (and how) firms respond to departures of $u$ from $u_{n}$, but also the value of $u_{n}$ itself. Hence according to Setterfield and Avritzer (2019), it is erroneous to assume that macroeconomic volatility can be taken as given and that as such, the normal rate of capacity utilization (designed, per Steindl (1952), to insulate firms from unforeseen variations in demand and hence potential loss of market share to competitors) can be treated as constant Amadeo, 1987). Instead, volatility rises sharply during the brief but profound crises that end "long booms" in macroeconomic performance (such as the periods 1948-73 and 1990-2007 in the US), which observation can be used as a basis for furnishing a behavioural theory of precisely 
the hysteresis closure in equation (2) that is favoured by Botte (2019).

One important caveat that emerges from Setterfield and Avritzer (2019) is that firms' assessment of the volatility of the macroeconomic environment (and hence their behaviour based on this assessment) may vary discretely rather than continuously. According to Setterfield and Avritzer (2019), volatility rises sharply during the severe crises that end long booms, and although these sharp rises are short-lived, it takes a substantial fall in volatility during the subsequent long boom to "reset" firms' assessment of the macroeconomic environment as being one of low volatility. The restlessness indicator proposed by Botte (2019), which varies continuously, does not capture this possibility. Setterfield and Avritzer (2019) thus argue that hysteresis in the normal rate of capacity utilization causes discrete (not continuous) variation in the normal rate over time (as a result of which equation (2) should be regarded only as a first approximation of variation in $u_{n}$ that is due to variation in $u$ ). Furthermore - and perhaps more significantly in the current context - Hartley (2019) finds evidence of regime-switching in investment spending congruent with discrete variations in investment behaviour resulting in discrete episodes of Harrodian instability despite continuous variation in the actual rate of capacity utilization (and departures from the normal rate). The latter observation can be explained by the actual rate wandering outside the time-varying tolerable range of intervals associated with the restlessness indicator only seldom, with the result that we get occasional bouts of Harrodian instability despite the more routine departure of $u$ from $u_{n} .^{2}$ But together with the evidence in Setterfield and Avritzer (2019), the possibility arises that the time-varying tolerable range itself varies only discretely, rather than continuously in the manner captured by the restlessness indicator.

The point remains, however, that the restlessness indicator (or some suitable re-specification thereof) proposed by Botte (2019) is a potentially valuable contribution. It may serve to

\footnotetext{
${ }^{2}$ This possibility is, of course, also consistent with Setterfield (2019a), despite constancy of tolerable range of variation in $u$ therein.
} 
enhance the literature investigating hysteresis in the normal rate of capacity utilization, as well as that investigating conditions under which the onset of Harrodian instability is likely.

\section{Conclusions and further reflections on the concept of corridor stability}

The analysis in Botte (2019) makes significant advances on that in Setterfield (2019a) which can, in turn, be thought of as preparatory to a "corridor within a corridor" approach to macrodynamics synethesising elements of Kaleckian and Harrodian theory. Within the first corridor (bounded by the tolerable interval of values of $u$ around $u_{n}$ ), growth cycles can develop within a Kaleckian framework owing to the interaction of short-run expectational disappointment and the state of long run expectations (Setterfield and Budd, 2011; Setterfield and Gouri Suresh, 2015). Outside this first corridor, meanwhile, Harrodian dynamics hold sway, albeit within bounds - the latter marking the limits of the second corridor within which the dynamics of the system are contained (Skott, 1989; Fazzari et al., 2013). Botte (2019) shows that the size of the first corridor is likely time-varying, because experience of macroeconomic volatility varies over time. In the first instance this suggests that the first (Kaleckian) corridor widens during severe crises, thwarting the onset of Harrodian dynamics that might otherwise propel the economy towards its potential output ceiling (what Botte (2019) calls a "muddy slump"). The picture emerges of a time-varying Kaleckian corridor within a fixed or constant Harrodian corridor. Further reflection, however, suggests that this is unlikely to be the case. In both Skott (1989) and Fazzari et al. (2013), the upper bound on Harrodian dynamics is related to supply constraints that create a potential output limit on activity at any point in time. But there is, of course, a large literature in macrodynamics suggesting that the economy's potential output path varies in response to its actual output path as a result of induced technological progress (the Verdoorn law) and/or the endogeneity 
of labour supply to the tightness of the labour market. This thinking has recently been embraced by Harrodians (?). Meanwhile, at least in the tradition represented by Fazzari et al. (2013), the lower bound on Harrodian dynamics is presented as an exogenous component of aggregate demand. Here, the analysis intersects with Sraffian supermultiplier analysis (Freitas and Serrano, 2015), in which the steady-state rate of growth is determined by an exogenous component of demand. Much of the controversy surrounding the Sraffian approach focuses on the likely endogeneity of alleged exogenous components of demand (Nikiforos, 2018; Skott, 2019), which, in turn, suggests the lower bound of the Harrodian corridor in Fazzari et al. (2013) may also be endogenous. Putting the pieces together suggests that Botte (2019) makes not only a valuable contribution to our understanding of the interaction of the actual and normal rates of capacity utilization, but also a potentially important step towards enabling synthesis of some of the main strands of thinking in contemporary heterodox macrodynamics writ large.

\section{References}

Amadeo, E. (1987). Expectations in a steady-state model of capacity utilization. Political Economy: Studies in the Surplus Approach 3(1), 75-89.

Avritzer, J. D. (2019). Three Essays on Income Distribution, Growth and Household Debt Dynamics. Ph. D. thesis, New School for Social Research, New York, in progress.

Botte, F. (2019). Estimating normal rates of capacity utilization and their tolerable ranges: a comment on Mark Setterfield. Cambridge Journal of Economics (forthcoming).

Cassetti, M. (2006). A note on the long-run behaviour of Kaleckian models. Review of Political Economy 18(4), 497-508.

Commendatore, P. (2006). Are Kaleckian models relevant for the long run? In N. Salvadori and C. Panico (Eds.), Classical, Neoclassical and Keynesian Views on Growth and Distribution. Cheltenham: Edward Elgar.

Dutt, A. K. (1997). Equilibrium, path dependence and hysteresis in post-Keynesian models. In P. Arestis, G. Palma, and M. Sawyer (Eds.), Capital Controversy, Post-Keynesian Economics and the History of Economic Thought: Essays in Honour of Geoff Harcourt. London: Routledge. 
Dutt, A. K. (2010). Equilibrium, stability and path dependence in Post Keynesian models of economic growth. In A. Birolo, D. Foley, H. D. Kurz, B. Schefold, and I. Steedman (Eds.), Production, Distribution and Trade: Alternative Perspectives. Essays in Honour of Sergio Parrinello. London: Routledge.

Fazzari, S. M., P. E. Ferri, E. G. Greenberg, and A. M. Variato (2013). Aggregate demand, instability, and growth. Review of Keynesian Economics 1(1), 1-21.

Freitas, F. and F. Serrano (2015). The Sraffian supermultiplier as an alternative closure to heterodox growth theory. Technical report, Instituto de Economia, Universidade Federal do Rio de Janeiro (UFRJ).

Hamilton, J. D. (2018). Why you should never use the Hodrick-Prescott filter. The Review of Economics and Statistics 100(5), 831-843.

Hartley, B. (2019). Title TBD. Ph. D. thesis, New School for Social Research, New York, in progress.

Hein, E., M. Lavoie, and T. van Treeck (2011). Some instability puzzles in Kaleckian models of growth and distribution: a critical survey. Cambridge Journal of Economics 35(3), $587-612$.

Hein, E., M. Lavoie, and T. van Treeck (2012). Harrodian instability and the "normal rate' of capacity utilization in Kaleckian models of distribution and growth - a survey. Metroeconomica 63(1), 139-169.

Kriesler, P. and J. W. Nevile (2012). Dynamic Keynesian economics: cycling forward with Harrod and Kalecki. Cambridge Journal of Economics 36(2), 405-417.

Lavoie, M. (1995). The Kaleckian model of growth and distribution and its Neo-Ricardian and Neo-Marxian critiques. Cambridge Journal of Economics 19(6), 789-818.

Lavoie, M. (1996). Traverse, hysteresis and normal rates of capacity utilization in kaleckian models of growth and distribution. Review of Radical Political Economics 28(4), 113-147.

Lavoie, M. (2010). Surveying short-run and long-run stability issues with the Kaleckian model of growth. In M. Setterfield (Ed.), Handbook of Alternative Theories of Economic Growth,. Cheltenham, UK: Edward Elgar.

Nikiforos, M. (2016). On the 'utilisation controversy': a theoretical and empirical discussion of the Kaleckian model of growth and distribution. Cambridge Journal of Economics $40(2), 437-467$.

Nikiforos, M. (2018). Some comments on the Sraffian supermultiplier approach to growth and distribution. Journal of Post Keynesian Economics 41(4), 659-675. 
Schüler, Y. S. (2019). How should we filter economic time series? Available at SSRN: http://dx.doi.org/10.2139/ssrn.3366923.

Setterfield, M. (2019a). Long-run variation in capacity utilization in the presence of a fixed normal rate. Cambridge Journal of Economics 43(2), 443-463.

Setterfield, M. (2019b). Time variation in the size of the multiplier: a Kalecki-Harrod approach. Review of Keynesian Economics 7(1), 28-42.

Setterfield, M. and J. D. Avritzer (2019). Hysteresis in the normal rate of capacity utilization: a behavioural explanation, New School for Social Research, mimeo.

Setterfield, M. and A. Budd (2011). A Keynes-Kalecki model of cyclical growth with agentbased features. In P. Arestis (Ed.), Microeconomics, Macroeconomics and Economic Policy: Essays in Honour of Malcolm Sawyer. Palgrave Macmillan.

Setterfield, M. and S. Gouri Suresh (2015). Firm performance, macroeconomic conditions, and 'animal spirits' in a Post Keynesian model of aggregate fluctuations. Journal of Post Keynesian Economics, forthcoming 38(1), 38-63.

Skott, P. (1989). Conflict and effective demand in economic growth. Cambridge, UK: Cambridge University Press.

Skott, P. (2010). Growth, instability and cycles: Harrodian and Kaleckian models of accumulation and income distribution. In M. Setterfield (Ed.), Handbook of Alternative Theories of Economic Growth. Cheltenham: Edward Elgar.

Skott, P. (2012). Theoretical and empirical shortcomings of the Kaleckian investment function. Metroeconomica 63(1), 109-138.

Skott, P. (2019). Autonomous demand, Harrodian instability and the supply side. Metroeconomica $70(2), 233-246$.

Steindl, J. (1952). Maturity and Stagnation in American capitalism. Oxford, UK: Blackwell. 